\title{
Infecção natural por Cryptosporidium sp. em aves domésticas comercializadas em mercados municipais do Estado do Rio de Janeiro
}

\author{
Natural infection by Cryptosporidium sp. In domestic fowls sold at local markets
}

\author{
Raquel Saucier Gomes ${ }^{\mathrm{I}}$ Teresa Cristina Bergamo do Bomfim ${ }^{\mathrm{*}}$ Franziska Huber $^{\mathrm{II}}$
}

\section{RESUMO}

O objetivo do trabalho foi comparar a dinâmica, a ocorrência, a morfometria de oocistos e os períodos patentes de Cryptosporidium sp. em aves domésticas, patos (Anas platyrhynchos), pintos (Gallus gallus) e codornas (Coturnix japonica), naturalmente infectadas, provenientes de dois mercados municipais do Estado do Rio de Janeiro, Rio de Janeiro (RJ). Houve diferenças quanto à ocorrência da infecção entre os dois locais e entre pintos e patos, mas não entre codornas. Para a morfometria, foram observadas diferenças estatísticas nas medidas dos diâmetros maior e menor e para o índice morfométrico calculado $(P<0,01)$. Já entre pintos $e$ codornas não houve diferenças $(P>0,05)$. Na comparação do período de eliminação, patos tiveram um maior período com maiores quantidades de oocistos eliminados. Codornas e pintos apresentaram dinâmica de eliminação semelhante e não houve diferença quanto à concentração de oocistos. Pintos foram mais susceptíveis à infecção seguidos por patos e codornas. Pode-se concluir que a infecção natural por Cryptoporidium sp. foi frequente nas aves estudadas. Patos, pintos e codornas podem ser disseminadores do protozoário em mercados municipais do Rio de Janeiro, RJ. Assim, podem constituir risco de infecção.

Palavras-chave: Cryptosporidium sp., infecção natural, patos (Anas platyrhynchos), pintos (Gallus gallus), codornas (Coturnix japonica), mercado municipal.

\section{ABSTRACT}

The objective of the current study was comparing the dynamic and occurrence of Cryptosporidium sp., as well as the morphometry and elimination period of oocysts in naturally infected ducks (Anas platyrhynchos), chickens (Gallus gallus) and Japanese quails (Coturnix japonica) from two local markets of Rio de Janeiro, RJ. There were significant differences considering the occurrence of infection between the two markets, and also between chickens and ducks, but not among Japanese quails. Also, significant statistical differences were observed in morphometry, considering the major and minor diameters of oocysts and the calculated morphometric index $(P<0.01)$; however, there was no difference between chickens and Japanese quails $(P>0.05)$. According to the elimination period, ducks eliminated oocysts for a longer period and in a higher number. Japanese quails and chickens had a similar dynamic of oocysts elimination, no difference in its concentration was observed. Chickens were the most susceptible bird species to Cryptosporidium sp. infection, followed by ducks and Japanese quails. In conclusion, Cryptosporidium sp. natural infection was commonly found in the studied fowls. Ducks, chickens and Japanese quails may disseminate this protozoan in local markets of Rio de Janeiro, representing risk of infection.

Key words: Cryptosporidium sp., natural infection, ducks (Anas platyrhynchos), young chickens (Gallus gallus) japanese quails (Coturnix japonica), local market.

\section{INTRODUÇÃO}

TYZZER (1929) descreveu o protozoário Cryptosporidium em cecos de frangos, que mais tarde foi nomeado de C. baileyi (CURRENT et al., 1986), sendo a primeira descrição do protozoário em aves. SLAVIN (1955) relatou um protozoário estruturalmente similar em perus, nomeando-o de Cryptosporidium meleagridis, atribuindo a ele mortalidade em perus jovens de uma criação comercial.

'Departamento de Parasitologia Animal, Instituto de Veterinária, Universidade Federal Rural do Rio de Janeiro (UFRRJ), BR 465, Km 7, 23890-000, Seropedica, RJ, Brasil. E-mail: tcbb@ufrrj.br. *Autor para correspondência.

"Fundação de Apoio à Escola Técnica do Estado do Rio de Janeiro, Instituto Superior de Tecnologia. Rua Sebastião de Lacerda Fábrica Paracambi, Rio de Janeiro, RJ, Brasil. 
Três espécies de Cryptosporidium são consideradas infectantes para aves domésticas e silvestres, sendo elas C. baileyi (CURRENT et al., 1986), C. meleagridis (SLAVIN, 1955) e C. galli (RYAN et al., 2003). Cryptosporidium meleagridis foi originalmente descrita parasitando o intestino de perus, $\boldsymbol{C}$. baileyi, a bursa de Fabricius, a cloaca e o trato respiratório de frangos e C. galli parasitando o proventrículo de pássaros (XIAO et al., 2004).

Várias possíveis novas espécies e novos genótipos têm sido encontrados em aves por meio da análise de caracterização molecular. Estudos de genotipagem de oocistos provenientes de patos negros e do ganso do Canadá que apresentavam criptosporidiose intestinal revelaram que essas aves não continham as espécies descritas até o presente momento, considerando dessa forma genótipos que não foram caracterizados como espécies (MORGAN et al., 2001). Em codornas, foi sugerida a existência de uma nova espécie de Cryptosporidium que apresentava oocistos similares a $\boldsymbol{C}$. meleagridis, mas que não existe em local definido (GUYOT et al., 2002).

A transmissão das espécies do gênero Cryptosporidium de animais domésticos para humanos foi observada por vários autores, havendo relatos de humanos que se infectaram após a exposição com animais parasitados (O'DONOGHUE, 1995). Atualmente sugere-se que aves possam ser reservatórios do protozoário para humanos, uma vez que a espécie $\boldsymbol{C}$. meleagridis pode também infectar humanos, sendo de importância para a saúde coletiva (XIAO et al., 2002).

Cryptosporidium meleagridis foi diagnosticado infectando sete crianças em Lima, no Peru, como causa de diarréia (XIAO et al., 2001) . Em pacientes portadores do vírus da imunodeficiência humana (HIV), foi constatado que a infecção por $\boldsymbol{C}$. hominis ocorreu em $67,5 \%$ dos pacientes, seguido por C. meleagridis presente em $12,6 \%$ das amostras fecais examinadas (CAMA et al., 2003).

Das 15 espécies nomeadas de Cryptosporidium, sete já foram implicadas em infecções humanas, dentre elas: C. baileyi, C. canis, C. felis, C. hominis, C. meleagridis, C. muris e $C$. parvum (FAYER, 2004).

O presente trabalho teve como objetivo diagnosticar a infecção natural de Cryptosporidium sp. em patos, pintos e codornas comercializados em mercados municipais do Estado do Rio de Janeiro, Brasil.

\section{MATERIAL E MÉTODOS}

Foram examinados 180 animais, obtidos em dois mercados municipais do Rio de Janeiro, Rio de Janeiro (RJ), para verificação da ocorrência de infecção natural por Cryptosporidium sp. em patos (Anas platyrhynchos), pintos (Gallus gallus) e codornas (Coturnix japonica). Os mercados foram escolhidos por conveniência. Foram escolhidos mercados situados em bairros da zona Norte (mercado I) e da zona Oeste (mercado II), ambos no Município do Rio de Janeiro. De cada mercado foi analisado um total de 90 animais, sendo 30 de cada espécie. Os patos e pintos tinham menos de uma semana de idade, e as codornas, mais de 30 dias. As condições de higiene do local de comercialização dos animais foram avaliadas englobando: aspectos da criação; contato com outras espécies de animais e com humanos; local de manutenção das aves nas gaiolas; o estado sanitário dos animais expostos; e a proximidade das lojas de comercialização de animais com as lojas de produtos alimentícios. As aves adquiridas foram alojadas em gaiolas individuais, com fundo gradeado, recebendo à vontade água e ração específica para a espécie. A cada ida aos mercados era adquirido um lote com 10 aves de cada espécie. As aves positivas ou não permaneciam no biotério, onde só estavam os animais do presente estudo, até cessar a eliminação de oocistos nas fezes, sendo comprovada por três exames seguidos negativos. A cada troca de lote de animais, era realizada rigorosa higienização nas gaiolas e no local de abrigo dessas aves, com hipocloreto de sódio seguido de vassoura de fogo. Para verificar a ocorrência de Cryptosporidium sp., foram realizados exames coproparasitológicos pela técnica de centrífugoflutuação nas amostras provenientes dos 180 animais adquiridos nos dois mercados. O processo usado foi a observação das amostras em microscópio óptico com e sem contraste de fase, com objetiva de 40x e de 100x. Coletas diárias de fezes foram realizadas para acompanhamento infecção natural por Cryptosporidium sp. Para verificar a infecção natural por Cryptosporidium sp. nas aves, foi feita a quantificação dos oocistos eliminados. A metodologia utilizada foi a de quantificação dos oocistos, por contagem direta em lâminas, segundo MCLAUCHLIN et al. (1999). Foram contados oocistos presentes em pelo menos 30 campos da microscopia, no aumento de 40x. Após a contagem, foram realizadas a estimativa e a classificação de oocistos por campo, em relação à quantidade de oocistos por campo de microscopia. Os animais foram acompanhados até o término da eliminação de oocistos. Depois de coletadas, as fezes 
foram pesadas $(4 \mathrm{~g})$, homogeneizadas com água destilada $(14 \mathrm{ml})$ e filtradas em tamis de plástico descartáveis contendo gaze. O material fecal filtrado foi acondicionado em tubos de $15 \mathrm{ml}$ cônicos e centrifugado a 402,48xg, por 10 minutos. Após esse procedimento, o sobrenadante foi desprezado, e adicionou-se solução saturada de açúcar $(\mathrm{d}=1,33)$, que foi homogeneizada e centrifugada a 402,48g, por cinco minutos, ao sedimento. Posteriormente, o tubo foi completado com solução de açúcar e coberto com uma lamínula, ficando em repouso por três minutos. A lamínula foi montada sobre uma lâmina de vidro e examinada em microscópio óptico com e sem contraste de fase, em objetiva de 40x e de 100x. Para a realização da morfometria dos oocistos, utilizou-se ocular morfométrica, acoplada ao microscópio óptico, sem contraste de fase. Das amostras fecais positivas para Cryptosporidium sp., foram medidos os oocistos em micrômetros $(\mu \mathrm{m})$ e foram calculados os seus índices morfométricos. Para a análise estatística, foram utilizados o teste t de Student e o Qui-quadrado.

\section{RESULTADOS E DISCUSSÃO}

Do mercado municipal I, 29 (96,7\%) patos, $20(66,6 \%)$ codornas e $30(100 \%)$ pintos apresentaram eliminação de oocistos de Cryptosporidium sp.. No mercado municipal II, 17 (56,7\%) patos, 13 animais $(43,3 \%)$ codornas e 22 animais $(73,3 \%)$ pintos apresentaram eliminação de oocistos de Cryptosporidium sp.. Diferenças significativas foram encontradas na infecção entre os mercados para patos $(\mathrm{P}<0,01)$ e pintos $(\mathrm{P}<0,01)$. Porém, na comparação entre as amostras provenientes das codornas dos dois mercados, essa diferença não ocorreu $(\mathrm{P}=0,069)$.

As taxas de infecção de Cryptosporidium sp. nos patos foram semelhantes às encontradas na literatura por GRACZYK et al. (1996), os quais observaram $100 \%$ dos animais eliminando oocistos de Cryptosporidium, demonstrando a susceptibilidade do hospedeiro nessa espécie de ave. MORGAN et al. (2001) relataram a susceptibilidade de codornas e pintos à infecção pelo protozoário. Porém, a menor taxa de infecção apresentada por estas pode estar associada à influência das idade dos hospedeiros, pois estas são comercializadas após 30 dias de nascidas, enquanto pintos e patos são comercializados com até uma semana de idade.

As altas taxas de infecção encontradas nas espécies de aves do presente estudo podem estar relacionadas também com as condições sanitárias observadas nos dois mercados. As condições sanitárias observadas não eram satisfatórias, pois ambos os mercados apresentaram pouca higiene, não havendo limpeza periódica das gaiolas, troca e limpeza adequadas dos bebedouros e retirada de fezes ou de animais mortos. Além disso, havia alta aglomeração de aves, que, muitas vezes, apresentaram-se mantidas com as outras espécies, possíveis hospedeiras para protozoários do gênero, aumentando o risco para aquisição da infecção.

A diferença encontrada entre patos e pintos pode estar relacionada ao número maior de estabelecimentos de comercialização encontrados no mercado I em relação ao II e ao maior número de aviários, tendo assim um número maior de animais, possivelmente infectados, os quais podem gerar contaminação ambiental, com a dispersão do protozoário.

Neste estudo, as codornas tinham mais de 30 dias e provavelmente estavam aptas a combaterem as reinfecções devido a respostas da imunidade mais eficiente. Esse fato também foi observado por TUMOVÁ et al. (2002), isto é, animais mais velhos apresentaram maior resistência à infecção, pois possuem sistema imunológico competente.

Os oocistos provenientes dos patos dos mercados municipais I e II apresentaram respectivamente $6,1 \pm 0,4$ e 5,9 $\pm 0,5$ (diâmetro maior); 4,5 $\pm 0,3$ e 4,4 40,4 (diâmetro menor) e 1,3 $\pm 0,1$ (índice morfométrico) (Tabela 1). Quando comparadas as morfometrias dos isolados de Cryptosporidium sp., não foram encontradas diferenças significativas nos diâmetros maiores $(\mathrm{P}=0,09)$ e menores $(\mathrm{P}=0,16)$. O índice morfométrico calculado também não apresentou diferenças significativas $(\mathrm{P}=0,36)$.

No caso das codornas, as médias dos oocistos provenientes dos mercados municipais I e II foram respectivamente, $6,0 \pm 0,5$ e 6,2 $\pm 0,4$ (diâmetro maior); $5,1 \pm 0,6$ e 4,6 $\pm 0,3$ (diâmetro menor) e 1,2 $\pm 0,1$ e $1,4 \pm 0,1$ (índice morfométrico). Esses dados de biometria dos oocistos, obtidos dos animais provenientes dos dois mercados, foram valores semelhantes aos limites descritos para as espécies Cryptosporidium baileyi (CURRENT et al.,1986). SRETER \& VARGA (2000) demonstraram que oocistos dessa espécie mediam 6,2 x 4,6ì m. Assim, pode-se sugerir que essa mesma espécie de Cryptosporidium poderia estar infectando patos nos dois mercados municipais estudados. Entretanto, para a comprovação desses resultados, seria necessária a caracterização molecular proveniente desses isolados. Deve-se ressaltar a alta variação dentro de uma mesma espécie e a igualdade morfométrica que existe entre algumas espécies de Cryptosporidium (XIAO et al. 2004; EYGED et al. 2003).

Ciência Rural, v.39, n.7, out, 2009. 
Tabela 1 - Dados morfométricos (média e desvio padrão $\mu \mathrm{m}$ ) dos oocistos de Cryptosporidium sp. de patos, codornas e pintos provenientes de dois mercados municipais do Rio de Janeiro, Rio de Janeiro (RJ).

\begin{tabular}{|c|c|c|c|c|c|c|}
\hline \multicolumn{3}{|c|}{ Espécie de aves } & \multirow{2}{*}{$\frac{\text { Mercado I }}{6,1 \pm 0,4}$} & \multirow{2}{*}{$\frac{\text { Mercado II }}{5,9 \pm 0,5}$} & \multirow{2}{*}{$\frac{P}{0,09^{2}}$} & \multirow{2}{*}{$\frac{\mathrm{T}}{1,72}$} \\
\hline & & DM & & & & \\
\hline Pato & & $\mathrm{Dm}$ & $4,5 \pm 0,3$ & $4,4 \pm 0,4$ & $0,16^{2}$ & 1,43 \\
\hline \multirow{4}{*}{ Codorna } & & $\mathrm{IM}$ & $1,3 \pm 0,1$ & $1,3 \pm 0,1$ & $0,71^{2}$ & 0,36 \\
\hline & & $\mathrm{DM}$ & $6,0 \pm 0,5$ & $6,2 \pm 0,4$ & $0,29^{2}$ & $-1,16$ \\
\hline & & Dm & $5,1 \pm 0,6$ & $4,6 \pm 0,3$ & $0,01^{1}$ & \multirow[t]{2}{*}{3,62} \\
\hline & & IM & $1,2 \pm 0,1$ & $1,4 \pm 0,1$ & $0,01^{1}$ & \\
\hline \multirow{6}{*}{ Pinto } & \multirow{2}{*}{$\mathrm{I}$} & DM & $5,8 \pm 0,7$ & $5,8 \pm 0,7$ & 0,95 & \\
\hline & & Dm & $4,6 \pm 0,4$ & $4,7 \pm 0,5$ & 0,79 & $-0,26$ \\
\hline & \multirow{4}{*}{ II } & $\mathrm{IM}$ & $1,3 \pm 0,2$ & $1,3 \pm 0,1$ & 0,71 & 0,37 \\
\hline & & DM & $4,8 \pm 0,6$ & - & - & - \\
\hline & & Dm & $3,4 \pm 0,8$ & - & - & - \\
\hline & & $\mathrm{IM}$ & $1,5 \pm 0,4$ & - & - & - \\
\hline
\end{tabular}

${ }^{1}$ Significativo pelo teste Qui-quadrado.

${ }^{2}$ Não significativo pelo teste Qui-quadrado.

$\mathrm{DM}=$ Diâmetro maior.

Dm=Diâmetro menor

$\mathrm{IM}=$ Índice morfométrico.

Comparando-se as morfometrias dos oocistos, foram encontradas diferenças significativas nos diâmetros maiores $(\mathrm{P}=0,25)$. Porém, nos menores não houve diferenças significativas $(\mathrm{P}>0,01)$ no índice morfométrico, o que pode estar relacionado ao fato proposto por MALLON et al. (2003), os quais sugerem que o protozoário é capaz de realizar recombinações intraespecíficas, em seu estágio sexuado, fazendo com que vários subtipos provenientes de uma mesma espécie apareçam nessas aves, assim as medidas poderiam ser diferentes, porém se trataria de subtipos de uma mesma espécie.

Em relação aos oocistos provenientes de pintos, foram observadas diferenças estatisticamente significativas na morfologia e no índice morfométrico entre oocistos provenientes de amostras de pintos de um mesmo mercado. As médias para oocistos provenientes de pintos do mercado municipal I apresentaram diâmetros maiores variando entre $5,8 \pm 0,7$ e $4,8 \pm 0,6$ e menores variando entre $4,6 \pm 0,4$ e $3,4 \pm 0,8$,

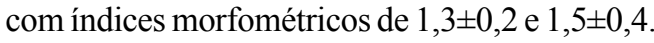

No mercado municipal II, encontraram-se diâmetros, os maiores de $5,8 \pm 0,7$ e os menores de $4,7 \pm 0,5$

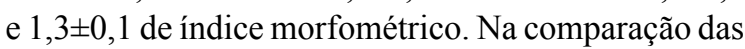
medidas dos oocistos provenientes de pintos dos dois mercados estudados, observou-se que no mercado I os oocistos eram diferentes e foram classificados em dois tamanhos (Pinto I e Pinto II), ocorrendo diferenças significativas quando comparados (Tabela 1). No mercado II, foi observado apenas um tamanho de oocisto.

Para pintos do mercado I, possivelmente foram encontradas duas espécies. Essa conclusão foi baseada em dados de morfometria dos oocistos. As medidas encontradas neste trabalho podem ser comparadas aos oocistos medidos por ARROWOOD (1997), que encontrou 5.2 x 4.3 ì m e índice morfométrico de 1.0-1.3, caracterizando como oocistos de Cryptosporidium meleagridis. a outra possível espécie de Cryptosporidium envolvida e que também acometia pintos no mercado II. Essa espécie se assemelha mais à descrita por CURRENT et al. (1986), medindo 6.2 x $4.5 \mathrm{ì} \mathrm{m}$ e caracterizada como Cryptosporidium baileyi. Porém, para confirmação definitiva da espécie, mais estudos serão necessários com base na biologia molecular de isolados provenientes dos mercados.

Em relação aos períodos de eliminação de oocistos da infecção natural (Figura 1), patos começaram a eliminar oocistos a partir do sexto dia e apresentaram dois picos: o primeiro $11^{\circ}-12^{\circ}$ dias e o segundo no $26^{\circ}$ dia, apresentando eliminação intermitente até $69^{\circ}$. Codornas começaram eliminar oocistos a partir do $2^{-}-3^{\circ}$ dias, com pico no $8^{\circ}$ dia, com início do decréscimo a partir do 9o dia. Pintos apresentaram a infecção a partir do 3 - dia, apresentando 


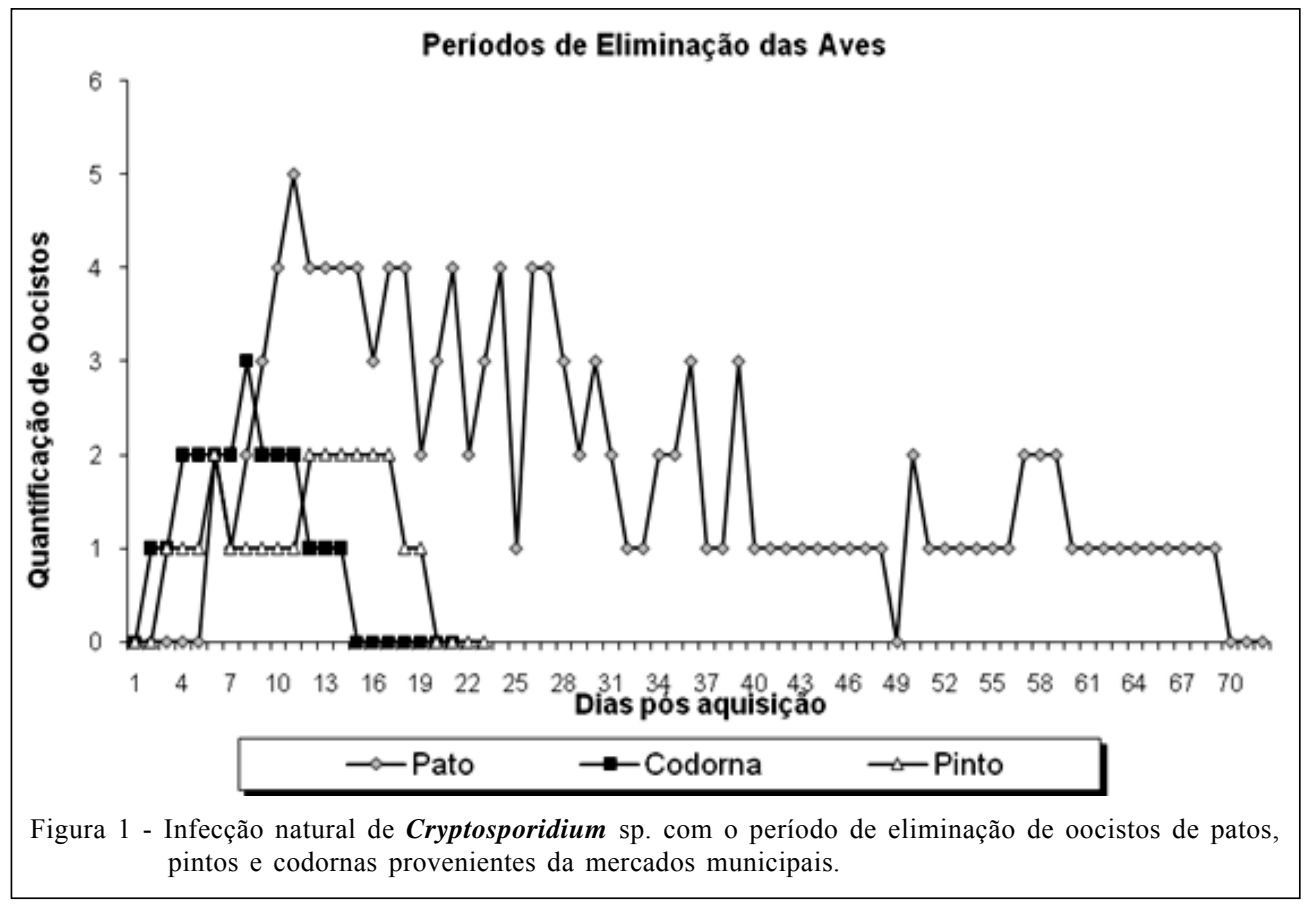

pico nos $5^{\circ}-6^{\circ}$ dias com eliminação intermitente até $19^{\circ}$ dia. Os resultados encontrados para períodos desde o início de eliminação e término de patos foram compatíveis aos encontrados na literatura por GRACZYK et al. (1996), os quais relataram período patente de dois dias. RHEE et al. (1995) encontraram o período pré-patente de 3-4 dias, o que poderia ter ocorrido devido a variações individuais na dinâmica da eliminação de oocistos de Cryptosporidium sp. relatada por GRACZYK et al. (1995). Em codornas e pintos, os períodos foram semelhantes entre eles de 23 dias, os quais estão de acordo com os observados por MEIRELES et al. (1995), MEIRELES et al. (1998) e RHEE et al. (1996).

Nos patos, o período de eliminação, além das altas concentrações de oocistos observados nas fezes, em comparação com codornas e pintos, poderia tornar esse hospedeiro em uma alta fonte de contaminação ambiental, não só no local de comercialização, mas também para outros ambientes aos quais os animais seriam destinados.

Em codornas e pintos, observou-se eliminação semelhante, não havendo diferença entre as concentrações de eliminação e o período de eliminação dos oocistos. Porém, essas aves também podem ser consideradas como fontes de contaminação ambiental independentemente da finalidade à qual serão destinadas.
Em relação à diferença observada entre as três espécies de aves, pode-se ressaltar que a variação intraespecífica é bem relatada na literatura: muitos autores afirmam que cada indivíduo possuiu uma imunidade específica e reage à infecção de forma diferenciada (HORNOK et al., 1998). No entanto, variação interespecífica foi observada nos resultados do presente trabalho: patos pertencem à classe dos Anseriformes e apresentaram diferença significativa quando comparados com pintos e codornas, ambos pertencentes à classe dos Galliformes, e estes não apresentaram diferenças entre si. Já que a fonte de infecção era a mesma, poder-se-ia sugerir que essa diferença poderia estar relacionada aos hospedeiros, por pertencerem a grupos taxonômicos distintos apresentam diferenças que refletiram na susceptibilidade ao parasitismo.

\section{CONCLUSÕES}

A infecção natural por protozoários do gênero Cryptoporidium foi verificada em aves domésticas (patos, pintos e codornas) comercializadas em dois mercados municipais no Rio de Janeiro. As aves comercializadas no mercado I podem estar infectadas por duas espécies diferentes do protozoário. Mais estudos devem ser realizados para elucidação de fatores de risco associados à infecção por Cryptosporidium sp., assim como estudos da caracterização molecular dos isolados.

Ciência Rural, v.39, n.7, out, 2009. 


\section{AGRADECIMENTOS}

Ao Conselho Nacional de Desenvolvimento Científico e Tecnológico (CNPQ), à Coordenação de Aperfeiçoamento de Pessoal de Nível Superior (Capes) e ao Curso de Pós-graduação em Ciências Veterinárias da UFRRJ pelo suporte financeiro.

\section{REFERÊNCIAS}

ARROWOOD, M.J. Diagnosis. In: FAYER, R. Cryptosporidium and cryptosporidiosis. Washington: CRC, 1997. p.43-60.

CAMA, V.A. et al. Cryptosporidium species and genotypes in HIV-positive patients in Lima, Peru. Journal of Eukariotic Microbiology, v.50, p.531-533. 2003. Disponivel em: <http: /www3.interscience.wiley.com/journal/119191844/ abstract?CRETRY $=1 \&$ SRETRY $=0>$. Acesso em: mai 2009 . doi: $10.1111 /$ j.1550-7408.2003.tb00620.x.

CURRENT, W.L. et al. The life cycle of Cryptosporidium baileyi, n. sp. (Apicomplexa: Cryptosporidiidae) infecting chickens. Journal of Protozoology, v.33, p.289, 1986. Disponivel em: < http://www3.interscience.wiley.com/journal/ 119501316/abstract>. Acesso em mai: 2009. doi: 10.1111/ j.1550-7408.1986.tb05608.x.

EYGED, Z.et al. Characterization of Cryptosporidium spp. recent developments and future needs. Veterinary Parasitology, v. 111, p.103-114, 2003. Disponível em: <http:// www.sciencedirect.com/science?_ob=ArticleURL\&_udi=B6TD7$475 \mathrm{RFK} 4-1 \& \_$user $=10 \& \_$rdoc $=1 \&$ fmt $=$ \&_orig $=$ search \& sort $=$ $\mathrm{d} \& \mathrm{vi}$ e w $=\mathrm{c} \&$ a c c t $=\mathrm{C} 000050221 \&$ \&ersion $=1$ $\&$ urlVersion $=0 \&$ u serid $=10 \&$ m d $5=579 d$ ba $87 b c 0 d 8339 a b 05 b 3109997 b 190>$. Acesso em: mai 2009. doi:10.1016/S0304-4017(02)00362-X.

FAYER, R. Cryptosporidium: a water-borne zoonotic disease. Veterinary Parasitology, v.126, p.37-56, 2004. Disponível em: $<\mathrm{h} \mathrm{t} \mathrm{t} \mathrm{p} \mathrm{:} \mathrm{/} \mathrm{/} \mathrm{w} \mathrm{w} \mathrm{w.} \mathrm{s} \mathrm{c} \mathrm{i} \mathrm{e} \mathrm{n} \mathrm{c} \mathrm{ed} \mathrm{i} \mathrm{r} \mathrm{e} \mathrm{c} \mathrm{t} \mathrm{c} \mathrm{o} \mathrm{m} \mathrm{/}$ science?_ob=ArticleURL\&_udi=B6TD7-4DN1HXV$2 \&$ user $=10 \&$ rdoc $=1 \& \mathrm{fmt}=\&$ orig $=$ search $\&$ sort $=\mathrm{d} \&$ view $=\mathrm{c} \&$ \&act $=\mathrm{C} 000050221 \&$ \& version $=1 \&$ \&urlVersion $=$ $0 \&$ userid $=10 \& \mathrm{md} 5=\mathrm{c} 4 \mathrm{cf} 1645 \mathrm{~d} 2 \mathrm{cb} 51187 \mathrm{~d} 4 \mathrm{~b} 2 \mathrm{c} 3211 \mathrm{~d} 6 \mathrm{f} 044>$. Acesso em: mai 2009. doi:10.1016/j.vetpar.2004.09.004.

GRACZYK, T.K. et al. Viability and infectivity of Cryptosporidium parvum oocysts are retained upon intestinal passage though a refratory avian host. Applied Enviromental Microbiology, v.62, p.3234-3237, 1996.

GUYOT, K. et al. PCR-restriction fragment lenght polymorphism analysis of a diagnostic 452-base-pair DNA fragment discriminates between Cryptosporidium parvum and C. meleagridis and beteween C. parvum isolates of human and animal origin. Applied Enviromental Microbiology, v.68, p. 2017-2076, 2002. Disponível em: <http://aem.asm.org/cgi/ content/full/68/4/2071>. Acesso em: maio 2009. doi: 10.1128/ AEM.68.4.2071-2076.2002.

HORNOK, S. et al. Interection of chicken anaemia virus and Cryptosporidium baileyi in experimentally infected chickens. Veterinary Parasitology, v.76, p.43-55, 1998. Disponível em: $<\mathrm{ht} \mathrm{t}$ p:// w w w. s c i e n c e direct. com/ science? ob=ArticleURL\& udi=B6TD7-3TC139DJ\&_user $=10 \bar{E}$ _rdoc $=1 \&$ fmt $=\&$ \&orig $=$ search\&_sort $=\mathrm{d} \&$ view $=\mathrm{c} \&$ _acct $=$ C $000050221 \&$ version $=1 \&$ ur 1 Version $=0 \&$ userid $=10 \& \mathrm{md} 5=\mathrm{b} 593 \mathrm{e} 1 \mathrm{~d} 57 \mathrm{c} 05 \mathrm{fa} 3 \mathrm{f} 09 \mathrm{e} 868507052 \mathrm{dd} 87>$. Acesso em: mai 2009. doi:10.1016/S0304-4017(97)00046-0.

MALLON, M. et al. Population structures and the role of genetic exchange in the zoonotic pathogen Cryptosporidium parvum. Journal Molecular Evolution, v.56, p.407-417, 2003. Disponível em: <http://www.springerlink.com/content/ nnfw9nt0fwdxq0xg/>. Acesso em: mai 2009. doi: 10.1007/ s00239-002-2412-3.

MCLAUCHLIN, J. et al. Genetic characterization of Cryptosporidium straisn from 218 patients with diarrhea diagnosed as having sporadic cryptosporidiosis. Journal Clinical Microbiology, v.37, p.3153-3158, 1999.

MEIRELES, M.V. et al. Correlação entre Toxoplasma gondii e Cryptosporidium baileyi em frangos de corte experimentalmente infectados. Revista Brasileira de Parasitologia Veterinária, v.4, p.105-112, 1995.

MEIRELES, M.V. et al. Infecção experimental por Cryptosporidium baileyi em aves de corte: I- aspectos clínicos, parasitológicos e zootécnicos. Revista Brasileira de Parasitologia Veterinária, v.7, p.11-14, 1998.

MORGAN, U.M. et al. Molecular phylogenetic characterization of Cryptosporidium from birds. International Journal for Parasitology, v.31, p.289-296, 2001. Disponível em: <http://www.sciencedirect.com/ science?_ob=ArticleURL\&_udi=B6T7F-42D 811 P $8 \&$ user $=10 \&$ rdoc $=1 \&$ fmt $=\&$ orig $=$ search \& sort $=\mathrm{d} \&$ view $=\mathrm{c} \&$ acct $=$ C $000050221 \&$ version $=1 \&$ \& ur 1 Version $=$ $0 \&$ userid $=10 \& \mathrm{md} 5=7 \mathrm{ae} 77675370684$ ecf9ca6faca2cd9d36>. Acesso em: mai 2009. doi:10.1016/S0020-7519(00)00164-8.

O'DONOGHUE, P.J. Cryptosporidium and cryptosporidiosis in man and animals. International Journal for Parasitology, v.25, p.139-195, 1995.

RHEE, J.K. et al. Oocyst procuction and imugenity of Cryptosporidium baileyi in chickens and mallards. Korean Journal Parasitology, v.33, p.45-54, 1995.

RHEE, J.K. et al. Chonologic change serum IgG antibody response on chickens reinfected with Cryptosporidium baileyi. Korean Journal Parasitology, v.34, p.255-258, 1996.

RYAN, U.M. et al. A redescrition of Cryptosporidium galli Pavlasek, 1999 (Apicomplexa : Cryptosporiididae) from birds. Journal of Parasitology, v.89. p.809-913, 2003.

SLAVIN, D. Cryptosporidium meleagridis. Journal of Compendiun patholology, v.65, p.262-266, 1955

SRÉTER, T.; VARGA, I. Cryptosporidiosis in birds - A review. Veterinary Parasitology, v.87, p.261-279, 2000.

TUMOVÁ, E. et al. Performance and oocyst shedding in broiler chickens orally infected with Cryptosporidium baileyi and Cryptosporidium meleagridis. Avian Diseases, v. 46, p.203207, 2002. 
TYZZER, E.E. Coccidiosis in gallinaceous birds. American Journal of Hygiene, v.10, p.269-383, 1929.

XIAO, L. et al. Identification of 5 types of Cryptosporidium parasites en children in Lima, Peru. Journal Infecion Diseases, v.183, p.492-497, 2001.

XIAO, L. et al. Cryptosporidium taxonomy: recent advances and implications for public health. Clinical Microbiology Review, v.17, p.72-97, 2004.
XIAO, L. et al. Host adaptation and host-parasite co-evolution in Cryptosporidium : implications for a taxonomy and public health. International Journal for Parasitology, v.32, p.1773-1785, 2002. Disponível em: http:// w w w. $\mathrm{s}$ c i e $\mathrm{n}$ c e d i r e c t . c o m / science? ob=ArticleURL\& udi=B6T7F-46VJDPH\&_user $=10 \& \_$rdoc $=1 \&$ fmt $=\&$ orig $=$ search $\& \_$sort $=d \&$ view $=$ c\&_acct $=$ C $000050221 \&$ \&ersion $=1 \&$ \&urlVersion $=0 \&$ \& serid $=10 \& \mathrm{md} 5=0355 \mathrm{ed} 418516 \mathrm{df} 467838 \mathrm{~d} 7473 \mathrm{f} 01 \mathrm{~d} 788>$. Acesso em: mai 2009. doi:10.1016/S0020-7519(02)00197-2.

Ciência Rural, v.39, n.7, out, 2009. 